\title{
Small hydroelectric plants: the hydraulic auger
}

\author{
G. Perillo \\ Department of Technology, Naples Parthenope University, Italy
}

\begin{abstract}
Small-scale hydroelectric plants are an important source of renewable energy and can actively contribute to the sustainable development of the local area, while also being cost-competitive with other renewable energy sources. This paper presents the application of a hydraulic auger used for flow rates up to $5-6 \mathrm{~m}^{3} / \mathrm{s}$ and heads up to $10 \mathrm{~m}$. Unlike other turbines, this equipment works by gravity with water producing torque on a transmission driving a generator connected to the auger in order to produce electricity. We present a case study on a plant located at an existing dam where, by evaluating the river's mean daily flow, we have obtained duration curves that make it possible to determine the power and annual energy production obtainable from the plant. This is then compared with the energy that can be obtained from a plant equipped with a Banki-Mitchell turbine, highlighting that, at equal flow rates, the annual production obtainable from the two systems is nearly the same, confirming the effectiveness of the inverse auger in the energy production process. The economic aspects are then analyzed by comparing the plant construction costs with revenues from energy sales.
\end{abstract}

Keywords: hydroelectric plants, hydraulic auger, turbine comparison.

\section{Introduction}

The use of hydraulic energy dates back to ancient times and, ever since its origins, hydro-electricity has been the most widely used source of renewable energy after biomass.

The first dam known to mankind was built around 4000 BC in Egypt, its purpose being to divert the flow of the Nile and establish the city of Memphis on the reclaimed land. Many ancient dams, including those built by the Babylonians, were part of complex irrigation systems which transformed barren regions into fertile plains. The main 'inanimate' source of energy in the ancient 
world was the so-called Greek mill, comprising a vertical wooden plank with small blades on the lower end submerged in the water, which was mainly used to grind wheat.

The Romans used hydraulic energy to till their fields instead of using horses and, by $85 \mathrm{BC}$, the kinetic energy of a river or the potential energy of a waterfall were exploited to power simple machines. A type of watermill with a horizontal axis and a vertical wheel was designed by the military engineer Vitruvius in the $1^{\text {st }}$ century BC and mills of noteworthy dimensions were built in the Roman Empire from the $4^{\text {th }}$ century AD.

In the Middle Ages, the Islamic world made important contributions to hydraulics. In the geographical area where the first Islamic civilizations developed, important work to reclaim land and distribute water was carried out.

Between the $9^{\text {th }}$ and the $10^{\text {th }}$ centuries, the need to find an energy source alternative to muscle power led to the considerable technical development of water-powered machines. In England, the Doomsday Book (the record of a census commissioned by William I in 1086) reported the presence of 5,624 water mills. This number gradually rose to 20,000 but the power generated by these water mills rarely exceeded $10 \mathrm{~kW}$. In 1770, the French engineer Bernard Forest de Bélidor wrote the book "Architecture Hydraulique" in which he described hydraulic machines with horizontal and vertical axes.

The first important attempt to formulate a theoretical basis for the design of water wheels was carried out in the $18^{\text {th }}$ century by the British civil engineer John Smeaton, who was the first to build large, cast-iron water wheels. The Frenchman Jean-Victor Poncelet came up with the idea of an underwater wheel with curved blades, which increased efficiency by $70 \%$.

Another French engineer, Claude Burdin, invented the term "turbine", introducing it into a theoretical relationship in which he highlighted the importance of the rotation velocity; Benoit Fourneyron designed and built impellers for the French ironworks which reached speeds exceeding 60 RPM and generated power up to $50 \mathrm{HP}$. It was the British-American engineer James B. Francis who, in 1849, designed a turbine with a centripetal flow, i.e. in which the flow was directed inwards.

The first hydroelectric plant was built in Northumberland in 1880. In 1858 Antonio Pacinotti built the first dynamo and in 1860 the first direct current electric engine. In 1895 Le Blanch experimented with the brushed DC electric motor to be inserted in cascade with an induction motor. The combination of hydraulic turbines and electric current gave birth to the use of hydroelectric energy on an industrial scale, based on a technology that has remained almost unaltered to the present day [1-3].

According to the classification adopted by UNIDO (United Nations Industrial Development Organization), hydroelectric plants can be classified on the basis of their rated power as follows:

- Micro hydroelectric plant $\mathrm{P}<100 \mathrm{~kW}$;

- Mini hydroelectric plant $\mathrm{P}<1.000 \mathrm{~kW}$;

- Small hydroelectric plant $\mathrm{P}<10.000 \mathrm{~kW}$;

- Large hydroelectric plant $\mathrm{P}>10.000 \mathrm{~kW}$. 
It is worth remembering that, in terms of power classification, the term 'Small Hydro Power' (SHP) refers to hydroelectric plants capable of producing a maximum of $10 \mathrm{MW}(10,000 \mathrm{~kW})$.

\section{Current world situation}

Hydraulic energy amounts to a quarter of the total energy produced in the world and its importance has been increasing in recent years.

Hydroelectric power production was prominent at the beginning of the 1960s when, due to the progressive use of available hydraulic resources, it stabilized at around 40-50 billion $\mathrm{kWh}$ per year, with oscillations caused mainly by the different hydraulic conditions over the years. In percentage terms, hydroelectric production, which in the 1960 s constituted $82 \%$ of the total power production, fell to $25 \%$ in the 1980 s, while thermoelectric production increased in the same time frame from $14 \%$ to $70 \%$.

Today, over $20 \%$ of the world's energy production comes from hydroelectric power plants, for a rated power of $870 \mathrm{GW}$.

The market for large hydroelectric plants is almost saturated, especially in Europe, so increasing importance is being attributed to smaller plants. Furthermore, while large hydroelectric plants require large surface areas, which causes a considerable environmental and social impact, a smaller plant will integrate itself perfectly into the local ecosystem, since it exploits the flow of the river directly $[4,5]$. Such plants have a number of advantages:

- Their installation is very straightforward and can be carried out in short construction times;

- $\quad$ They require only a limited water supply to generate electricity;

- $\quad$ The plants are usually located near the users, which minimizes energy loss due to electricity transport;

- $\quad$ They occupy less space.

There is no specific law concerning the classification of small hydroelectric plants, however the literature offers the following definitions:

- $\quad$ micro-turbines, machines with $\mathrm{P} \leq 100 \mathrm{~kW}$;

- $\quad$ mini-turbines, machines with power between $100 \mathrm{~kW}$ and $3 \mathrm{MW}$;

- $\quad$ small turbines, machines with power between $3 \mathrm{MW}$ and $12 \mathrm{MW}$.

Various turbines are present on the international market, a brief description of which is given below [6-8].

\subsection{Pelton Turbine}

The Pelton Turbine was invented by the carpenter Lester Allen Pelton in 1879, and to this day it is still the most efficient turbine and very simple to operate. The way it works resembles the classic mill wheel, but revised and corrected to increase efficiency. This type of turbine is generally used for large heads (between 20 and $200 \mathrm{~m}$ ) and modest flow rates Q. 


\subsection{Turgo turbine}

The Turgo turbine is an impulse turbine. It works with heads between 10 and $300 \mathrm{~m}$ and has a maximum output of 5MW. It differs from the Pelton turbine in that the blades have a different shape and arrangement and the jet hits several of them at the same time. The smaller diameter of the Turgo turbine makes it possible to have a higher angular velocity, so there is no need for a gearbox coupled to the generator. This reduces costs and increases the mechanical reliability of the system.

\subsection{Francis turbine}

The Francis turbine is a reaction turbine developed in 1848 by James B. Francis, a British engineer who moved to the United States. The Francis Turbine makes use of lower heads and considerable water flow rates; it is suitable for heads between 10 and $350 \mathrm{~m}$ and generates power between $0.2 \mathrm{MW}$ and a maximum of 10MW.

\subsection{Axial flow turbine (Kaplan)}

In the Kaplan turbine (or similar) the water runs through the wicket gate with a flow normal to the machine's rotation axis; therefore, the water will have to move through about $90^{\circ}$ to run axially over the runner, which obviously causes loss. In order to reduce this drawback, tubular axial turbines (TAT) have been built and patented for fairly large heads (up to 30-40 meters) and generating power from 0.3 MW up to $10 \mathrm{MW}$.

\subsection{Bulb turbine}

The bulb turbine is a reaction turbine which has both a generator and a gear box, if present, inside a watertight, bulb-shaped housing submerged in water. The bulb turbine, like all tubular axial turbines, is not equipped with a spiral case supplying the runner and is inserted directly inside the penstock. This allows for considerable engineering savings and simplifies routine maintenance operations. Water flow variation is much lower than in normal axial tubular turbines, even if the axis is horizontal.

\subsection{Banki-Mitchell turbine}

This kind of turbine is not suitable for use in large plants, but only in small-scale ones. It is well adapted for medium-low heads (from a few meters up to 200 meters) and for low power production, and hence also low flow-rate, below $700-800 \mathrm{~kW}$. This impulse turbine is also called the Cross Flow or Ossberger turbine, after the factory that has manufactured it for over 50 years. It is a twostage machine, which allows a double action of the water on the blades. Although its efficiency is less than $87 \%$, it remains constant when the flow-rate falls as low as $16 \%$ of the nominal flow and can, in theory, operate with a minimum flow rate $10 \%$ lower than that envisaged in the design specifications. 
Figure 1 shows a diagram from which the applicability field of the above mentioned turbines can be determined, at least in a first approximation.

\subsection{Inverse hydraulic auger}

The hydraulic auger employs the same principle as the Archimedes' screw, used by the ancient Egyptians to transport water for irrigation.

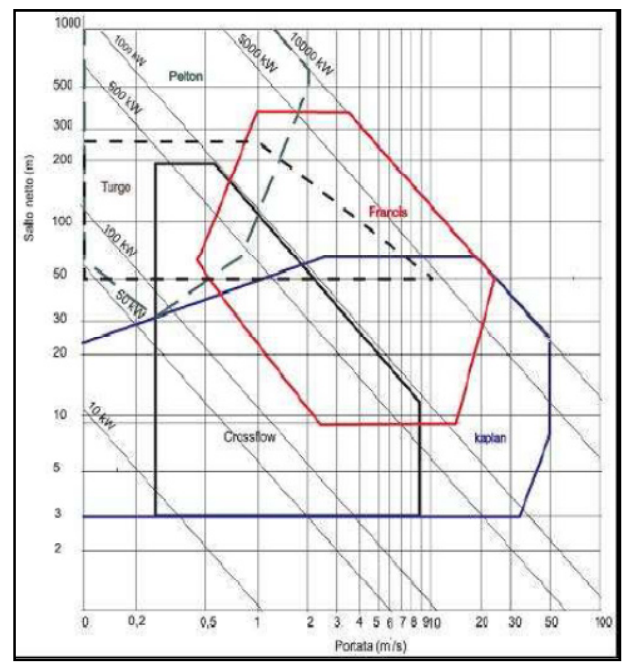

Figure 1: $\quad$ Performance curve of the hydraulic auger (red line) compared.

According to this principle, the energy is transferred to a shaft/rotor and the water is transported upwards. A power-generating machine can be made by using this principle in the inverse way. Unlike the above-mentioned turbines, the hydraulic auger harnesses gravity to work, i.e. water flows downwards from the higher chambers to the lower ones. In so doing, the falling water generates a torque on the transmission shaft. Since the auger must extend from the upper water surface to the lower one, it can only be used for short heads. The design flow determines the angle of incidence of the helix, the number of revolutions and the external diameter, while the head determines the length of the auger. The auger is manufactured by welding an optimized-flow helix onto a stiffened hollow shaft. The motor assembly comprises elastic joints, support frames, gear box, generator and, if needed, a transmission belt.

These augers can be used to harness hydraulic energy at flow rates between 0.2 and $5.5 \mathrm{~m}^{3} / \mathrm{s}$ and for a maximum head of $10 \mathrm{~m}$.

Hydraulic augers do not require the fine-mesh grills used in turbines and water wheels to prevent flotsam and fish from entering the machinery. This means that there is no loss of energy due to head reduction or a fall in performance because of the grills. 


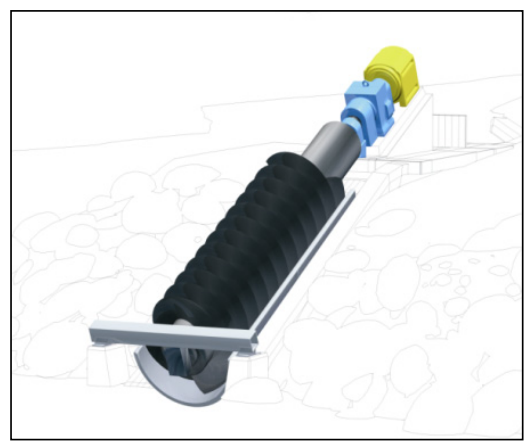

Figure 2: $\quad$ Inverse hydraulic auger.

The wide-mesh grill $(10-20 \mathrm{~cm})$ greatly reduces the formation of debris, and hence lowers costs for cleaning and related disposal operations, as any flotsam entering the plant is transported downstream. Variations in flow rate have a negligible impact on performance and do not affect the operation and service of the hydraulic auger. Very low flow rates do not damage the hydraulic auger and hydroelectric power plants fitted with them are therefore more feasible than traditional turbine-driven plants. As can be seen in the figure reported below, the performance of hydraulic augers can be as high as $90 \%$ and is, in any case, high in a range from one third of the flow rate to the maximum flow rate. This means that hydraulic augers achieve a high performance even when water supply is low.

Moreover, dams and turbines generally represent a major obstacle and a threat not only for fish heading upstream but also for migratory fish. Hydroelectric plants of any kind also constitute an obstacle for fish migrating to lay eggs. Experts' tests on hydraulic augers, on the other hand, have shown that both small fish (longer than $8 \mathrm{~cm}$ ) and large fish (up to $58 \mathrm{~cm}$ ) can pass through the plant unharmed, making the inverse hydraulic auger 'fish-sustainable' [9].

\section{Case study}

The study focuses on the possible installation of an inverse auger hydroelectric plant at the Persano dam (figure 3) situated between the Picentini and the Alburni mountains (Italy) at an elevation of 52.10m asl and measuring $158.80 \mathrm{~m}$ in length.

The foundations of the dam comprise layers of cemented large conglomerate over an impermeable concrete diaphragm covering 2500 square meters. The dam has four gates in line between five concrete piles (figure 2). The dam continues onto the left bank with a masonry structure. The gates have a $17 \mathrm{~m}$ aperture and are $6 \mathrm{~m}$ in height and are balanced with counterweights set in shafts inside the piles and are opened/closed by acting on the water level in the shafts. Obviously the speed with which the gates can be opened or closed depends on the quantity of water evacuated from or diverted into the shafts housing the floats. 


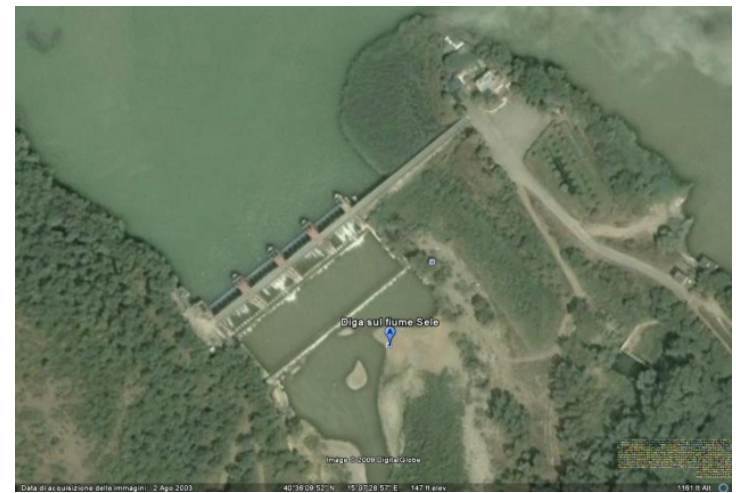

Figure 3: $\quad$ Aerial image of the dam.

Plant maintenance can be performed by diverting the course of the river to a spillway located along the left bank at $38.20 \mathrm{~m}$ asl. This spillway also has a gate measuring $4.8 \mathrm{~m} \mathrm{x} 4 \mathrm{~m}$ and can divert a flow of about $50 \mathrm{~m}^{3} / \mathrm{s}$. The dam greatly reduces the river flow velocity, which results in the depositing of large quantities of silt and sand both at the mouth of the spillway and in the shafts housing the floats that operate the gates. These areas therefore need to be dredged periodically to ensure efficient plant operation. This dam has raised the river level by $6 \mathrm{~m}$ (from $40.50 \mathrm{~m}$ to $46.50 \mathrm{~m}$ ) and created a reservoir in a large bend in the river Sele which is also supplied by its tributaries (the Tanagro and the Tenza).

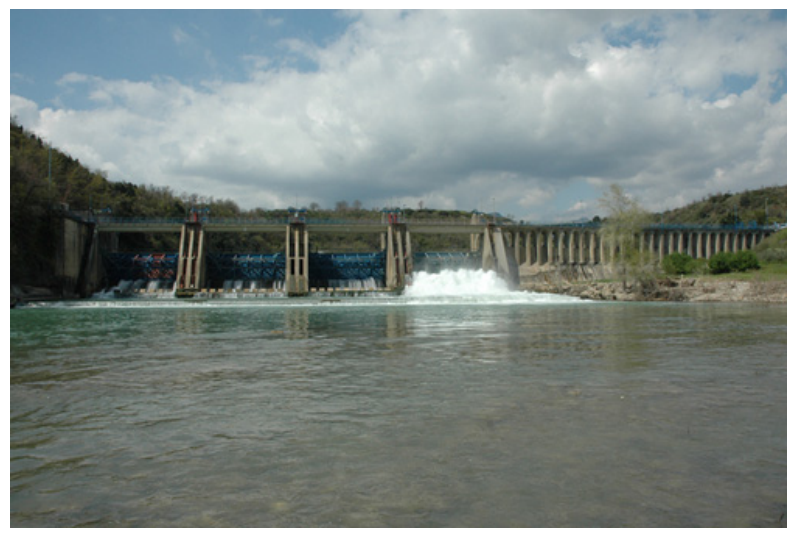

Figure 4: $\quad$ Frontal view of the dam.

The main data for the reservoir are as follows:

- maximum reservoir height:

- maximum regulation height:

- minimum regulation height:
$46.50 \mathrm{~m}$ asl.

$46.50 \mathrm{~m}$ asl.

$43.50 \mathrm{~m}$ asl. 
- freewater surface

1. at maximum reservoir height: $\quad 0.6 \mathrm{~km}^{2}$

2. at maximum regulation height: $\quad 0.6 \mathrm{~km}^{2}$

3. at minimum regulation height: $\quad 0 \quad \mathrm{~km}^{2}$

- total reservoir volume: $\quad 1.5 \times 10^{6} \mathrm{~m}^{3}$

- regulation working volume: $\quad 1 \times 10^{6} \mathrm{~m}^{3}$

- lamination volume: $\quad 0 \quad \mathrm{~m}^{3}$

- directly subtended basin surface area: $2336 \mathrm{~km}^{2}$.

The first step was to calculate the confined flow from the gates; as already mentioned, these are $17 \mathrm{~m}$ in length and are regulated automatically. Raising the gates allows the water to flow into the afterbay. System operation is similar to that of a sluice, as the entire aperture is below the freewater surface.

The data provided by the Bonifica Destra Sele Consortium for the period 2003-2009 made it possible to calculate the river's mean daily flow rate. The calculations performed made it possible to obtain the duration curves for every year from 2003. Of course, the measured flow rates vary from day to day between a maximum and a minimum.

The inverse auger plant was located on one of the two diversion channels on the hydraulic right which are used for irrigating the fields in the Sele valley. The water from the reservoir is diverted into these channels only during the irrigation season (essentially from June to September). In our case, as the aim is to site the production plant on the diversion works and as it would be necessary to have a constant supply throughout the year, it was decided that the augers should be installed immediately downstream of the diversion works with a spillway immediately downstream of the turbines to channel the water back into the river when irrigation is not required. The Bonifica Destra Sele Consortium has provided us with the data necessary for our case study. Specifically:

- $\quad$ the diverted flow varies between $4 \mathrm{~m} 3 / \mathrm{s}$ and $8 \mathrm{~m} 3 / \mathrm{s}$;

- the bottom of the diversion tunnel is at an elevation of $43.70 \mathrm{~m}$ asl;

- the reservoir elevation is, as already mentioned, $46.50 \mathrm{~m}$ asl and maintains this level for most of the year.

\section{Assessment of the power and energy produced}

Plant power can be obtained from the formula:

$$
P_{k W}=\frac{g \cdot \rho \cdot \eta \cdot H \cdot Q_{p}}{1000}
$$

where:

- $\quad g$ is the acceleration of gravity $=9.81 \mathrm{~m}^{2} / \mathrm{s}$;

- $\rho$ is the water density $=1000 \mathrm{~kg} / \mathrm{m}^{3}$;

- $\quad \eta$ is the plant efficiency;

- $\quad \mathrm{H}$ is the net head = reservoir height - height of the tunnel bottom, assumed to be $2.80 \mathrm{~m}$;

- Qp is the projected flow. 
The available data shows that the maximum flow rate obtainable from the diversion works is $8 \mathrm{~m}^{3} / \mathrm{s}$, which is greater than the maximum flow that the auger can manage. It was therefore initially decided that the power should be assessed with the plant operating at $Q_{p}=5.5 \mathrm{~m}^{3} / \mathrm{s}$, which is the maximum flow rate at which an auger can operate. Thus we calculated the percentage ratio between $\mathrm{Q}_{\mathrm{p}}$ and $\mathrm{Q}_{\max }$ (maximum flow that the plant can manage) which, in this case is $100 \%$ and, using the graph shown in figure 6 with the abscissa value known, the auger performance was calculated.

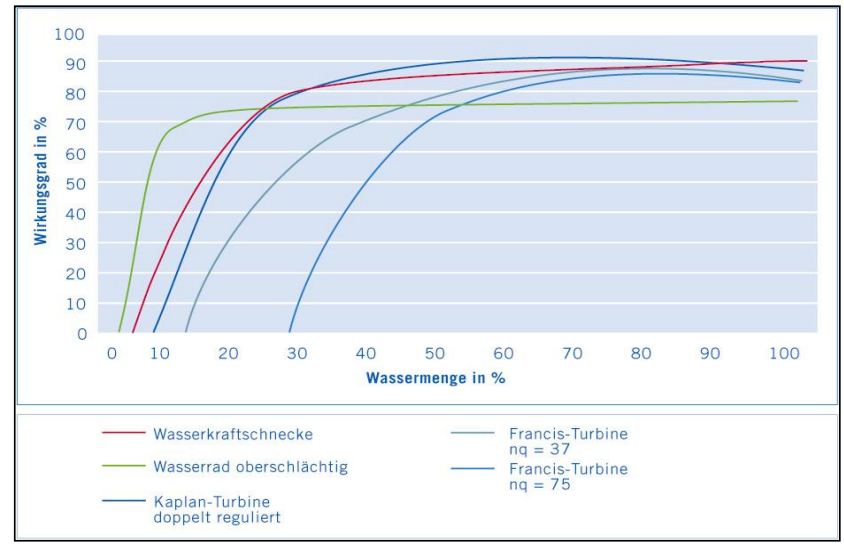

Figure 5: $\quad$ Auger performance curve (in red) compared.

We thus have all the data needed to calculate the power. The plant can be used with a flow rate which is at least $10 \%-12 \%$ of the maximum flow. For values below $10 \%$ of this figure, machine efficiency falls to zero. Adding the flow $Q_{p}$ to the DMV $\left(3.7 \mathrm{~m}^{3} / \mathrm{s}\right)$ yields the minimum flow in the river bed needed to ensure a flow to the auger of $Q_{p}$. At this point, it was possible to evaluate the number of days for which the flow rate in the river bed (specifically $9.2 \mathrm{~m}^{3} / \mathrm{s}$ ) is reached or exceeded.

Looking at the number of hours during which a flow rate of $5.5 \mathrm{~m}^{3} / \mathrm{s}$ is guaranteed then makes it possible to calculate the obtainable energy:

$$
E=P \cdot n[k W h]
$$

Obviously the plant will also work for $\mathrm{Q}_{\mathrm{p}}$ flows below the maximum rate. In a second stage this value was reduced in steps of $0.5 \mathrm{~m}^{3} / \mathrm{s}$ and the previously analysed calculations were repeated. For every step, therefore, it was possible to evaluate the power and the energy obtainable from the plant. The calculations then make it possible to evaluate the energy obtainable in a year from an inverse auger plant, which is:

$$
\mathrm{E}_{\text {total }}=752,216.7 \mathrm{kWh}
$$




\subsection{Comparison with a Banki-Mitchell mini-turbine}

In order to assess the economic viability of an inverse auger plant, its productivity was compared with that obtainable using Banki-Mitchell turbines. The latter was chosen because, as shown in section 2, it can exploit very low heads (we have a working head of $2.80 \mathrm{~m}$ ) as reported in figure 1.

The calculations were performed using the previously described procedure, initially hypothesising a maximum flow rate of $5.5 \mathrm{~m}^{3} / \mathrm{s}$ (like that considered for the inverse auger, while the maximum flow at which this turbine can operate is $12 \mathrm{~m}^{3} / \mathrm{s}$ ) , and then reducing the $Q_{p}$ value as previously, in steps of $0.5 \mathrm{~m}^{3} / \mathrm{s}$. Efficiency was assessed using the graph reported in figure 6 .

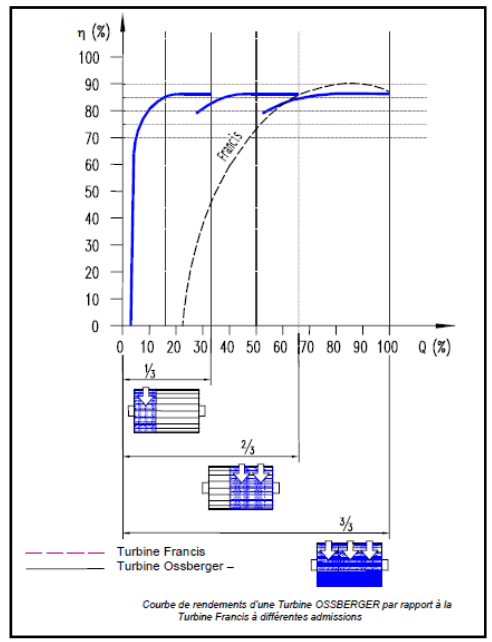

Figure 6: Banki-Mitchell performance curve.

The annual total energy obtained is:

$$
\underline{E}_{\text {total }}=729,891 \quad[\mathrm{kWh}] ;
$$

which is almost the same as the total energy obtainable from an inverse auger plant. This was expected, as a comparison of the two performance curves shows that for both plants the value of $\eta$ varies between 0.8 and 0.9 up to a percentage value of the $\mathrm{Q}_{\mathrm{p}} / \mathrm{Q}_{\max }$ ratio of around $10 \%$.

Then, given the characteristics of the Banki-Mitchell turbine, a maximum turbine flow rate of $8 \mathrm{~m}^{3} / \mathrm{s}$ (i.e. the $\mathrm{Q}_{\max }$ obtainable from the diversion works) was considered.

The annual total energy obtained is:

\section{$\underline{E}_{\text {total }}=997,157[\mathrm{kWh}]$.}

Another comparison was then performed between a plant fitted with a BankiMitchell mini-turbine $\left(Q_{p, \max }=8 \mathrm{~m}^{3} / \mathrm{s}\right)$ and a plant fitted with two inverse augers, each working with a maximum flow rate of $4 \mathrm{~m}^{3} / \mathrm{s}$. The calculations performed 
for the plant fitted with two inverse augers show that the annual productivity obtainable is:

$$
\underline{E}_{\text {total }}=1,099,520 \quad[\mathrm{kWh}] \text {. }
$$

Here too, the comparison shows that the annual productivity obtainable from the two plants is almost the same.

\section{Conclusions}

This paper has analysed the issue of small-scale hydroelectric power production. For almost 150 years, dams and hydroelectric power stations have been part of the mountain landscape, consolidating the idea that hydroelectricity is a clean, available and renewable energy resource $[10,11]$.

In particular, there are considerable environmental benefits in the construction of mini-hydroelectric plants: they can supply electricity to areas that would otherwise be isolated or reachable only with works having a greater environmental impact; they exploit water resources in a balanced way controlled by the communities involved; they contribute to reducing energy dependence on fossil fuels and do not produce greenhouse gases or other pollutants; moreover, by locating these plants near the users of the electricity produced, there is a much smaller network loss compared to large-scale hydroelectric plants.

Small-scale hydroelectric plants are therefore an important source of renewable energy and can actively contribute to the sustainable growth of the area in which they are situated.

If well located and appropriately sized, small-scale hydroelectric plants can also be economically competitive with other renewable energy sources and, considering the actual overall costs, even with traditional energy sources. On the basis of these considerations, we have specifically examined the feasibility of an inverse auger plant to be located on the Persano barrage dam, near the diversion and clarification works which channel the water from the river Sele into the fields in the Sele valley. The inverse auger works for small flows (up to a maximum of $5.5 \mathrm{~m}^{3} / \mathrm{s}$ ) and for small heads (10 m maximum). The head in the case in question $(2.80 \mathrm{~m})$ falls well within the auger's field of application. Moreover, thanks to the data provided by the Bonifica Destra Sele Consortium, it has been possible to determine that the maximum flow rate in the diversion channel is $8 \mathrm{~m}^{3} / \mathrm{s}$. Once the mean daily flows over the year were determined (a calculation performed using data provided by the Consortium for the period 2003-2009), the duration curves were obtained and the annual obtainable power and productivity of the plant were established for such conditions. A comparison was then made with the energy obtainable from a plant equipped with a BankiMitchell turbine, which highlighted that the annual obtainable productivity of the two plants was practically the same for the same flow rates, confirming the efficacy of the inverse auger in energy production. 


\section{References}

[1] C. d'Amelio, Elementi di macchine: Le turbine idrauliche. Fridericiana editrice Universitaria, 1991.

[2] F.H. White, Fluid Mechanic. McGraw-Hill, USA, 2001.

[3] Atlante europeo del potenziale idroelettrico minore (ATLAS). Institute of Hydrology of United Kingdom, UK, 2004.

[4] European commission, Externalities of Energy - vol.6: Wind and Hydro. Ed. EUR 16525 EN, 2005.

[5] De Siervo, Lugaresi, Moderns trends in selecting and designing Pelton turbines. Ed. Water Power and Dam Construction, 1988.

[6] Libro bianco Unione Europea, Energia per il futuro, le fonti energetiche rinnovabili. Ed. UE, 1997.

[7] N.H.C. Hwang and C. Hita, Fundamentals of hydraulic engineering systems. Ed. Prentice Hall Inc. Englewood Cliffs, New Jersey, 1987.

[8] Manual de minicentrales hidroelectricas. Ed. Cinco Dias, 1997.

[9] Massa Lugaresi, Moderns trends in selecting and designing Kaplan turbines. Ed. Water Power \& Dam Construction, 1989.

[10] Celso Penche, Guida all'idroelettrico minore - Per un corretto approccio alla realizzazione di un piccolo impianto. Ed. European small hydropower association (ESHA), Bruxelles, 1998.

[11] G. Raffaellini, Manuale di Progettazione HOEPLI, “Criteri Ambientali ed Impianti”vol.2. - Ed. Hoepli, Milano, 1994. 